\title{
The Relationship between Parkinson's Disease and Acute Myocardial Infarction in Korea : A Nationwide Longitudinal Cohort Study
}

\author{
Seung Hun Sheen, ${ }^{1, *}$ Je Beom Hong, ${ }^{2, *}$ Hakyung Kim, ${ }^{3}$ Jimin Kim, ${ }^{4}$ In-bo Han, ${ }^{1}$ Seil Sohn ${ }^{1}$ \\ Department of Neurosurgery, CHA Bundang Medical Center, CHA University, Seongnam, Korea \\ Department of Neurosurgery, Kangbuk Samsung Hospital, Sungkyunkwan University School of Medicine, Seoul, Korea \\ Genome \& Health Big Data Branch, ${ }^{3}$ Department of Public Health, Graduate School of Public Health, Seoul National University, Seoul, Korea \\ Cornell University, ${ }^{4}$ Ithaca, NY, USA
}

Objective : The goal of the following statewide age and gender-coordinated cohort study in Korea is to find out if there is a link between acute myocardial infarction (AMI) and Parkinson's disease (PD).

Methods : Utilizing the National Health Insurance Sharing Service cohort, patient data were collected. Six thousand four hundred seventy-five individuals with PD were distinguished by utilizing the International Classification of Diseases 10 code G20 and have enrolled in the PD group. The number of participants decreased to 5259 after excluding 1039 patients who were hospitalized less than one time or who visited an outpatient clinic less than twice. Then, 26295 individuals were selected as part of the control group after case control matching was conducted through 1:5 age- and gender-coordinated matching. The Cox proportional hazard regression analysis and Kaplan-Meier method were utilized to analyze the likelihood of AMI in PD.

Results : After controlling for age and gender, the hazard ratio of AMI in the PD group was 3.603 (95\% confidence interval [Cl], 2.837-4.577). After that, the following hazard ratio of AMI in the PD group was modified against for co-morbid medical disorders, resulting in 3.551 (95\% Cl, 2.795-4.511). According to a subgroup analysis, in males and females aged $<65$ and aged $\geq 65$ and in the non-diabetes and diabetes, hypertension and non-hypertension, dyslipidemia and non-dyslipidemia subgroups, the AMl incidence rates were dramatically higher in the PD group compared to that of the control.

Conclusion : Individuals with PD have a greater chance of AMI, according to this cross-national study.

Key Words : Parkinson's disease · Population · Myocardial infarction · Epidemiology.

\section{INTRODUCTION}

Parkinson's disease (PD) is a neurological disorder that worsens with time, which also affects the elderly population ${ }^{4)}$. In past examinations, it was found that ischemic heart disease reflects the highest mortality rate in patients with $\mathrm{PD}^{27,28)}$. A

- Received : July 29, 2021 •Revised : September 7, 2021 •Accepted : October 20, 2021

- Address for reprints : Seil Sohn

Department of Neurosurgery, CHA University College of Medicine, 59 Yatap-ro, Bundang-gu, Seongnam 13496, Korea

Tel : +82-31-881-7966, Fax : +82-31-780-5269, E-mail : sisohn@cha.ac.kr, ORCID : https://orcid.org/0000-0001-5724-8099

*Seung Hun Sheen and Je Beom Hong contributed equally as the first authors.

This is an Open Access article distributed under the terms of the Creative Commons Attribution Non-Commercial License (http://creativecommons.org/licenses/by-nc/4.0) which permits unrestricted non-commercial use, distribution, and reproduction in any medium, provided the original work is properly cited. 
population-based with matched participants revealed that PD was linked to a greater chance of acute myocardial infarction $(\mathrm{AMI})^{17)}$. Other studies, however, discovered that PD patients adapted a reduced risk of ischemic heart disease-related death $^{2,25)}$. According to recent research, PD is linked to hypertension and diabetes and other vascular risk factors ${ }^{3,26,34)}$. Since the two conditions are likewise AMI risk factors, these vascular comorbidities may defy the relationship between AMI and PD. In addition, earlier work focusing on the association between AMI and PD used a small size sample and the followup period was only 3 years ${ }^{17}$. This subsequent countrywide longitudinal research was not only based on how much data was available, but it was also adjusted to account for confounding variables such as hypertension, dyslipidemia, and diabetes. As a result, the goal of this cross-country study resulted in comparing the estimated percent of AMI in a PD group to a control group.

\section{MATERIALS AND METHODS}

The Review Committee of CHA Bundang Medical Center of CHA University gave us the rights to utilize it (IRB No. 2020-01-011).

\section{Data source}

South Korea's health-care system is single-payer run by the National Health Insurance Sharing Service (NHISS) ${ }^{1,14,15,23)}$. This service is operated through the medical claims that are submitted by health-care providers for a thorough review, as well as the numerous national health examinations provided bi-annually for office workers and annually for non-office workers, all aged $\geq 40$ years. These two procedures allows the NHISS to make available a clear database of those engaging in national health examinations ${ }^{32}$. Such a database incorporates recent medical procedures, treatments, demographics, and diagnoses from the International Classification of Diseases $\left(\right.$ ICD-10) ${ }^{13}$. To make use of the following NHIS-HEALS database, researchers are strongly advised to get permission from the official review committee.

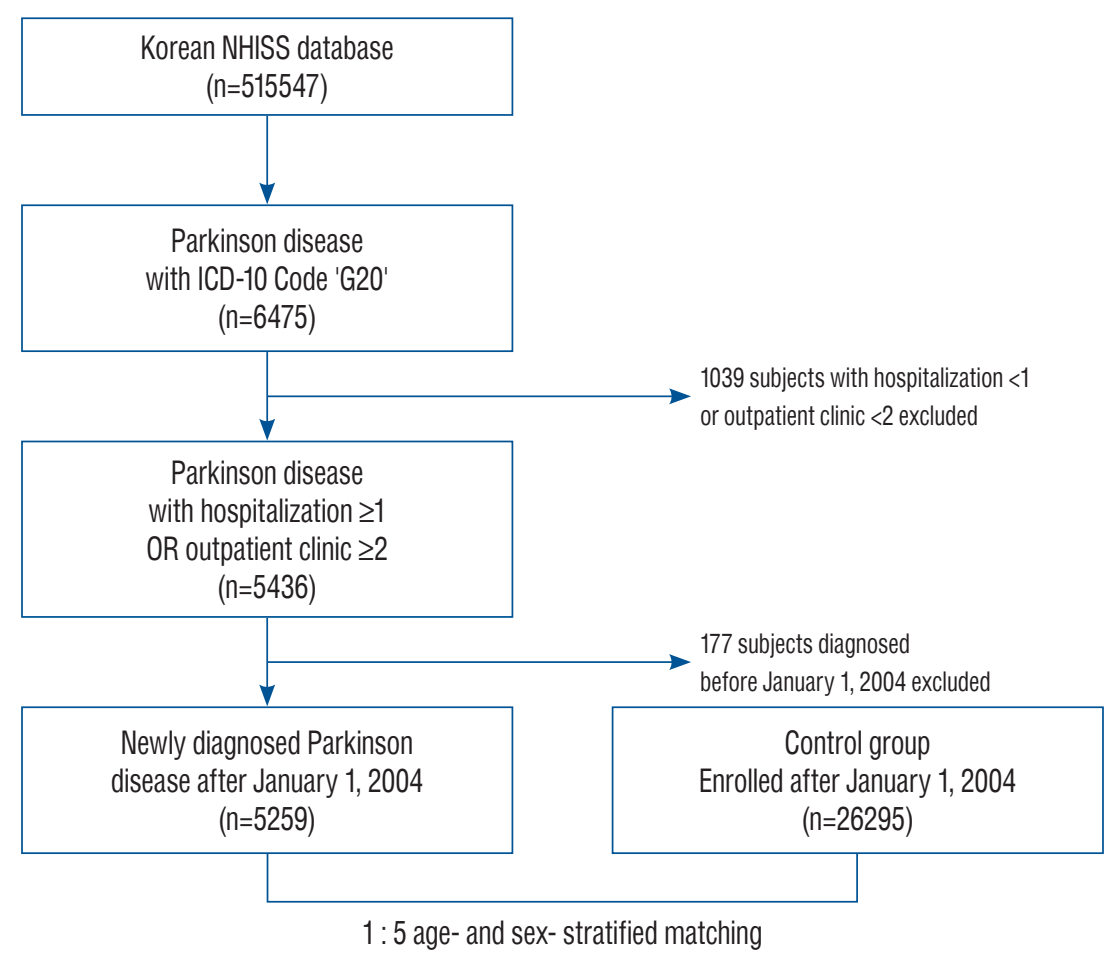

Fig. 1. The data formation process is depicted in this flow chart to support this 12-year cohort research utilizing the NHISS cohort. NHISS : National Health Insurance Sharing Service, ICD-10: International Classification of Diseases 10. 


\section{Study design and subjects}

The aim of this sex and age coordinated cohort analysis is to determine the potential risks of AMI in patients with PD. The study's subjects include a PD and control group. The Korea NIHSS cohort included 515547 participants, whose data have been in track until December 2015 (12 years). From this population, numerous factors such as age, income level, sex, ICD-10 disease codes, and preexisting comorbid medical disorders in the NHISS database played a role in classifying them into different categories ${ }^{16,24)}$. After such an adjustment, their risk of AMI and co-morbidities of dyslipidemia, diabetes mellitus, and hypertension were evaluated.

\section{Establishment of the study cohort}

Six thousand four hundred seventy-five PD patients were drawn out from the 515547 patients exhibited in the NHISS database using the code G20 based on the ICD-10 code, which helps identify researchers the presence of PD. Five thousand four hundred thirty-six people who were hospitalized more than once or who visited an outpatient clinic more than two times were selected. In addition, after excluding 177 subjects with preexisting PD, 5259 patients who were newly diagnosed after January 1, 2004 remained. Furthermore, to classify the control group, 26295 individuals were chosen through $1: 5$ sex and age coordinated matching without replacement with 'Match IT', a R-package match algorithm ${ }^{16)}$. The researchers have kept a close watch on both the PD and control groups until 31 December 2015 (Fig. 1).

\section{Statistical analysis}

To distinguish the mean differences in the control and PD groups' demographic features and co-morbidities, a statistical analysis was done using the chi-square test and student's t-test (Table 1). The Kaplan-Meier technique was used to look at the probability of surviving without an AMI. The Wilcoxon's log rank test was then used to assess the distinctions in survival percents between the two groups. To account for the influence of PD on each subsequent incident, two Cox proportionalhazards regression models were utilized. Model 1 was modified for gender and age. In addition, in model 2, sex, age, low income, and other variables were changed. $\mathrm{R}$ software was used to examine such exams (version 3.3.3; R Foundation for Statistical Computing, Vienna, Austria).

Table 1. Subgroup analyses between PD and control group

\begin{tabular}{|c|c|c|c|c|c|}
\hline \multirow{2}{*}{ Variable } & \multicolumn{2}{|r|}{ PD } & \multicolumn{2}{|c|}{ Control } & \multirow{2}{*}{ Hazard ratio $(95 \% \mathrm{Cl})$} \\
\hline & $\mathrm{N}$ & Incidence rate (\%) & $\mathrm{N}$ & Incidence rate (\%) & \\
\hline \multicolumn{6}{|l|}{ Sex } \\
\hline Male & 49 & 7.14 & 266 & 2.15 & $3.56(2.57,4.92)$ \\
\hline Female & 42 & 4.56 & 203 & 1.33 & $3.66(2.56,5.23)$ \\
\hline \multicolumn{6}{|l|}{ Age (years) } \\
\hline$<65$ & 41 & 4.78 & 162 & 1.06 & $4.85(3.34,7.04)$ \\
\hline$\geq 65$ & 50 & 6.67 & 307 & 2.48 & $2.88(2.10,3.95)$ \\
\hline \multicolumn{6}{|l|}{ Diabetes } \\
\hline No & 60 & 4.98 & 357 & 1.42 & $3.13(2.34,4.18)$ \\
\hline Yes & 31 & 6.50 & 112 & 2.02 & $4.49(2.92,6.91)$ \\
\hline \multicolumn{6}{|c|}{ Hypertension } \\
\hline No & 44 & 4.42 & 210 & 1.49 & $3.91(2.75,5.54)$ \\
\hline Yes & 47 & 12.43 & 259 & 2.98 & $3.29(2.37,4.57)$ \\
\hline \multicolumn{6}{|c|}{ Dyslipidemia } \\
\hline No & 73 & 5.46 & 361 & 1.59 & $3.72(2.84,4.87)$ \\
\hline Yes & 18 & 6.68 & 108 & 2.17 & $3.01(1.78,5.10)$ \\
\hline
\end{tabular}

$\mathrm{PD}$ : Parkinson's disease, $\mathrm{Cl}$ : confidence interval 


\section{RESULTS}

\section{Characteristics of the PD and control groups}

There were notable distinctions in the PD and control groups in both of their low income $(p<0.001)$, diabetes mellitus $(p=0.001)$, and hypertension $(p<0.001)$ (Table 2$)$.

The data showed 5259 patients who have been newly diagnosed with PD. The population consisted of a mean age of $62.87 \pm 8.42$ years, with $53.28 \%$ of them being male. The two groups were significantly different in terms of how common their low income $(p<0.001)$, diabetes mellitus $(p=0.001)$, and hypertension $(p<0.001)$ were.

Table 2. Characteristics of PD and control group

\begin{tabular}{lccc}
\hline Variable & PD $(\mathbf{n}=5259)$ & Control $(\mathbf{n}=26295)$ & $p$-value \\
\hline Male & $2802(53.28)$ & $14010(53.28)$ & \\
Age (years) & $62.87 \pm 8.42$ & $62.87 \pm 8.42$ & \\
Income low & $1305(24.81)$ & $7159(27.23)$ & $<0.001^{*}$ \\
Diabetes & $827(15.73)$ & $3678(13.99)$ & $0.001^{*}$ \\
Hypertension & $2338(44.46)$ & $12349(46.96)$ & $<0.001^{*}$ \\
Dyslipidemia & $91(1.73)$ & $4681(17.80)$ & 0.077 \\
AMl & $91(1.73)$ & $469(1.78)$ & 0.834 \\
\hline
\end{tabular}

Values are presented as mean \pm standard deviation or number (\%). *Indicates statistical significance. PD : Parkinson's disease, AMI : acute myocardial infarction

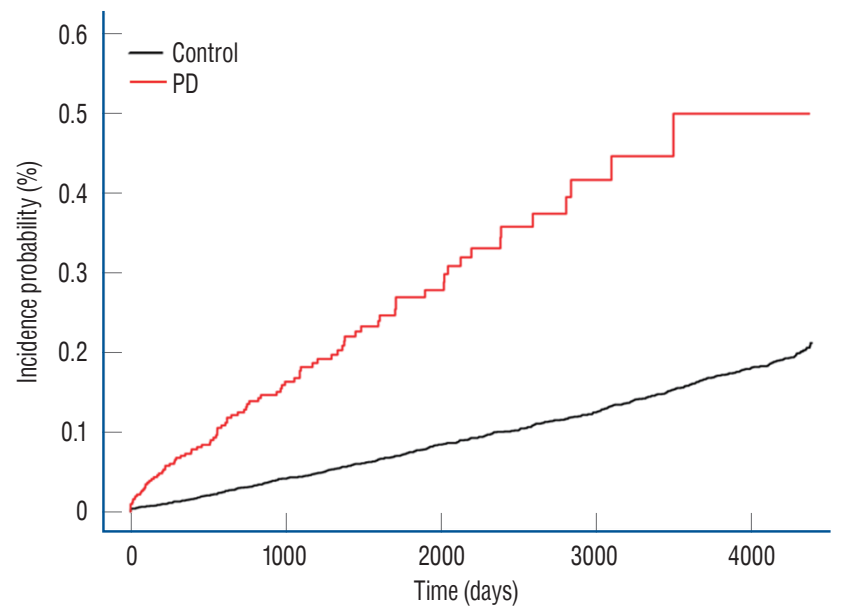

Fig. 2. The cumulative rates of acute myocardial infarction (AMI) in the Parkinson's disease (PD) and control groups were compared. The PD and control groups' cumulative risks of AMI were examined with KaplanMeier curves.

\section{$\mathrm{AMI}$ in the PD and control groups}

The chance of AMI in the PD group was significantly higher $(p<0.001$, Fig. 2$)$ than in the control group, as demonstrated by the Kaplan-Meier curves. In addition, a closer look at Cox proportional-hazards regression model 1 reveals that the $\mathrm{PD}$ group's AMI ratio was 3.603 (95\% confidence interval [CI], 2.83-4.57; Table 3), whereas model 2's ratio was 3.586 (95\% CI, 2.82-4.55; Table 3).

\section{Subgroup analysis of AMI incidence rate}

The AMI rates in the control and PD groups were much unalike in the female and male subgroups (95\% CI, 2.579-4.922 and 2.569-5.238, respectively; Table 1). Similarly, the same occurrence happened in the subgroups of age $<65$ and $\geq 65$ (95\% CI, 3.347-7.040 and 2.109-3.958, respectively; Table 1), nondiabetes and diabetes (95\% CI, 2.346-4.185 and 2.922-6.916, respectively; Table 1), non-hypertension and hypertension (95\% CI, 2.758-5.544 and 2.373-4.576, respectively; Table 1), non-dyslipidemia and dyslipidemia (95\% CI, 3.725-4.874 and 1.783-5.102, respectively; Table 1).

\section{DISCUSSION}

In this nationwide cohort study based on the NHISS database, 5259 PD patients had a significantly more prone to AMI. One population-based follow-up study conducted in Taiwan claimed that the AMI rate of the PD group was higher by 1.67 times compared to a control group ${ }^{17)}$. Our follow-up research, after modifying for important co-morbidities like age, sex, and income level, suggested that PD was affiliated with a 3.603-fold increased chance of AMI (Table 3). This data is syn-

Table 3. Adjusted hazard ratio for AMl event in PD and Control group

\begin{tabular}{lcc}
\hline & PD $(\mathbf{n}=\mathbf{5 2 5 9})$ & Control $(\mathbf{n}=\mathbf{2 6 2 9 5 )}$ \\
\hline Event & 91 & 469 \\
Duration (days) & 5858758 & 100599503 \\
Incidence rate (\%) & 5.669 & 1.702 \\
Hazard ratio (95\% Cl) & & \\
Model 1 & $3.603(2.83-4.57)$ & 1 \\
Model 2 & $5.607(4.49-6.99)$ & 1 \\
\hline
\end{tabular}

Model 1 : adjusted for age, sex; model 2 : adjusted for age, sex, income low, diabetes, hypertension, dyslipidemia. AMI : acute myocardial infarction, PD : Parkinson's disease, $\mathrm{Cl}$ : confidence interval 
chronous with previous research that also studied factors that affected PD patients' mortality rates and concluded that their death rates were linked to ischemic heart disease (hazard ratio, 2.3; 95\% CI, 1.5-3.4).

The mechanism of increased AMI in PD patients is unclear. One reasonable theory is that oxidative stress is present in idiopathic $\mathrm{PD}$, and these oxidative damage products interfere with cellular functions ${ }^{9,12)}$. According to previous research, systemic inflammation and oxidative stress were linked to atherosclerosis development ${ }^{9,18)}$ and danger of coronary artery disease $^{8,10,21)}$. As having PD may point to a higher oxidative stress accumulation, it indicates a higher incidence rate of AMI.

Orthostatic hypotension, usually due to the autonomic dysfunction in PD, is commonly seen in patients' cardiovascular systems ${ }^{7,31)}$ : a meta-analysis indicated that orthostatic hypotension is present in $30 \%$ of those with $\mathrm{PD}^{35)}$. Likewise, another study suggested that $48 \%$ of PD patients who were diagnosed over 20 years also suffered from the same symptom ${ }^{19)}$. Moreover, some research report that such a behavior is related to baroreflex failure, extracardiac noradrenergic denervation, and sympathetic denervation ${ }^{11)}$. However, it is known by many that those with orthostatic hypotension are more prone to coronary heart disease : a condition that can appear when there is decreased diastolic perfusion pressure of the myocardial blood flow ${ }^{6,20,29,36)}$.

Despite such different findings, various limitations of this study should be mentioned. For instance, the pathogenesis of atherosclerosis and $\mathrm{AMI}^{5,22,30,33)}$, and the inflammatory markers and chronic infectious burden, like interleukin-6 and Creactive protein, can be correlated with one another ${ }^{5,22,30,33)}$. Nonetheless, since information about inflammatory markers are not much available in the database, it is tough to analyze the possible effects of it on the relationship between AMI and $\mathrm{PD}^{16,32)}$. Nevertheless, though limitations can be seen, it is no doubt that this is the first longitudinal nationwide follow-up study that clearly assesses the relationship between AMI and PD in Korea.

\section{CONCLUSION}

The following nationwide longitudinal cohort study found that Korean PD patients, overall, have an increased risk of
AMI. Hence, this study suggests that the increased vulnerability of AMI should be deliberated on during PD patient care.

\section{CONFLICTS OF INTEREST}

No potential conflict of interest relevant to this article was reported.

\section{INFORMED CONSENT}

This type of study does not require informed consent.

\section{AUTHOR CONTRIBUTIONS}

\author{
Conceptualization : SHS, JBH, SS \\ Data curation : HK, JK, SS \\ Formal analysis : HK, IBH, SS \\ Funding acquisition : SHS, JBH, SS \\ Methodology : HK, SS \\ Project administration : JK, SS \\ Visualization : HK, JK \\ Writing - original draft : SHS, JBH \\ Writing - review \& editing : JK, SS
}

\section{ORCID}

$\begin{array}{ll}\text { Seung Hun Sheen } & \text { https://orcid.org/0000-0002-0454-8810 } \\ \text { Je Beom Hong } & \text { https://orcid.org/0000-0002-4812-565X } \\ \text { Hakyung Kim } & \text { https://orcid.org/0000-0003-2450-760X } \\ \text { Jimin Kim } & \text { https://orcid.org/0000-0002-2455-8290 } \\ \text { In-bo Han } & \text { https://orcid.org/0000-0002-0834-9325 } \\ \text { Seil Sohn } & \text { https://orcid.org/0000-0001-5724-8099 }\end{array}$

\section{- Acknowledgements}

The National Research Foundation of Korea's (NRF) Basic Science Research Program, supported by the Ministry of Education (NRF-2021R1I1A3058902), assisted the following nationwide longitudinal study. Furthermore, an endowment from the ICT, Ministry of Science, and future Planning (NRF- 
2020R1F1A1069875) was given to support our study.

\section{References}

1. Bae KH, Hong JB, Choi YJ, Jung JH, Han IB, Choi JM, et al. : Association of congestive heart failure and death with ankylosing spondylitis : a nationwide longitudinal cohort study in Korea. J Korean Neurosurg Soc 62 : 217-224, 2019

2. Beyer MK, Herlofson K, Arsland D, Larsen JP : Causes of death in a community-based study of Parkinson's disease. Acta Neurol Scand $103: 7-11,2001$

3. Cereda E, Barichella M, Pedrolli C, Klersy C, Cassani E, Caccialanza R, et al. : Diabetes and risk of Parkinson's disease: a systematic review and meta-analysis. Diabetes Care 34 : 2614-2623, 2011

4. de Lau LM, Breteler MM : Epidemiology of Parkinson's disease. Lancet Neurol 5 : 525-535, 2006

5. Fahdi IE, Gaddam V, Garza L, Romeo F, Mehta JL : Inflammation, infection, and atherosclerosis. Brain Behav Immun 17 : 238-244, 2003

6. Fedorowski A, Stavenow L, Hedblad B, Berglund G, Nilsson PM, Melander 0 : Orthostatic hypotension predicts all-cause mortality and coronary events in middle-aged individuals (the Malmo preventive project). Eur Heart J 31 : 85-91, 2010

7. Gołab-Janowska M, Budzianowska A, Honczarenko K : Autonomic disorders in Parkinson's disease. Ann Acad Med Stetin 57 : 11-15; discussion 16, 2011

8. Hansson GK : Inflammation, atherosclerosis, and coronary artery disease. N Engl J Med 352 : 1685-1695, 2005

9. Harrison D, Griendling KK, Landmesser U, Hornig B, Drexler $H$ : Role of oxidative stress in atherosclerosis. Am J Cardiol 91(3A) : 7A-11A, 2003

10. Heitzer T, Schlinzig T, Krohn K, Meinertz T, Münzel T : Endothelial dysfunction, oxidative stress, and risk of cardiovascular events in patients with coronary artery disease. Circulation 104 : 2673-2678, 2001

11. Jain S, Goldstein DS : Cardiovascular dysautonomia in Parkinson disease: from pathophysiology to pathogenesis. Neurobiol Dis 46 : 572-580, 2012

12. Jenner $\mathbf{P}:$ Oxidative stress in Parkinson's disease. Ann Neurol $\mathbf{5 3}$ Suppl 3 : S26-S36; discussion S36-S38, 2003

13. Kang SH, Choi EK, Han KD, Lee SR, Lim WH, Cha MJ, et al. : Underweight is a risk factor for atrial fibrillation: a nationwide populationbased study. Int J Cardiol 215 : 449-456, 2016

14. Kim YS, Kim JG, Yi J, Choi JM, Chung CK, Choi UY, et al. : Changes in the medical burden of pyogenic and tuberculous spondylitis between 2007 and 2016: a nationwide cohort study. J Clin Neurosci 73 : 8993, 2020

15. Lee DH, Choi YJ, Han IB, Hong JB, Do Han K, Choi JM, et al. : Association of ischemic stroke with ankylosing spondylitis: a nationwide longitudinal cohort study. Acta Neurochir (Wien) 160 : 949-955, 2018

16. Lee JK, Kim H, Hong JB, Sheen SH, Han IB, Sohn S: Association of acute myocardial infarction with seropositive rheumatoid arthritis in Korea: a nationwide longitudinal cohort study. J Clin Neurosci 78 : 97-101, 2020

17. Liang HW, Huang YP, Pan SL : Parkinson disease and risk of acute myocardial infarction: a population-based, propensity score-matched, longitudinal follow-up study. Am Heart J 169 : 508-514, 2015

18. Libby P, Ridker PM, Maseri A : Inflammation and atherosclerosis. Circulation $105: 1135-1143,2002$

19. Lim SY, Lang AE : The nonmotor symptoms of Parkinson's disease--an overview. Mov Disord 25 Suppl 1 : S123-S130, 2010

20. Luukinen H, Koski K, Laippala P, Airaksinen KE : Orthostatic hypotension and the risk of myocardial infarction in the home-dwelling elderly. J Intern Med 255 : 486-493, 2004

21. Madamanchi NR, Vendrov A, Runge MS : Oxidative stress and vascular disease. Arterioscler Thromb Vasc Biol 25 : 29-38, 2005

22. Mehta JL, Saldeen TG, Rand K : Interactive role of infection, inflammation and traditional risk factors in atherosclerosis and coronary artery disease. J Am Coll Cardiol 31 : 1217-1225, 1998

23. Park CJ, Choi YJ, Kim JG, Han IB, Do Han K, Choi JM, et al. : Association of acute myocardial infarction with ankylosing spondylitis: a nationwide longitudinal cohort study. J Clin Neurosci 56 : 34-37, 2018

24. Park CS, Choi EK, Han KD, Lee HJ, Rhee TM, Lee SR, et al. : Association between adult height, myocardial infarction, heart failure, stroke and death: a Korean nationwide population-based study. Int J Epidemiol 47 : 289-298, 2018

25. Pennington $S$, Snell K, Lee M, Walker $R$ : The cause of death in idiopathic Parkinson's disease. Parkinsonism Relat Disord 16 : 434-437, 2010

26. Qiu C, Hu G, Kivipelto M, Laatikainen T, Antikainen R, Fratiglioni L, et al. : Association of blood pressure and hypertension with the risk of Parkinson disease: the national FINRISK study. Hypertension 57 : 10941100,2011

27. Rektor I, Goldemund D, Sheardová K, Rektorová I, Michálková Z, Dufek $M$ : Vascular pathology in patients with idiopathic Parkinson's disease. Parkinsonism Relat Disord 15 : 24-29, 2009

28. Roos RA, Jongen JC, van der Velde EA : Clinical course of patients with idiopathic Parkinson's disease. Mov Disord 11 : 236-242, 1996

29. Rose KM, Tyroler HA, Nardo CJ, Arnett DK, Light KC, Rosamond W, et al. : Orthostatic hypotension and the incidence of coronary heart disease: the Atherosclerosis Risk in Communities study. Am J Hypertens 13(6 Pt 1) : 571-578, 2000

30. Ross R : Atherosclerosis--an inflammatory disease. N Engl J Med 340 : 115-126, 1999

31. Senard JM, Raï S, Lapeyre-Mestre M, Brefel C, Rascol O, Rascol A, et al. : Prevalence of orthostatic hypotension in Parkinson's disease. J Neurol Neurosurg Psychiatry 63 : 584-589, 1997

32. Seong SC, Kim YY, Park SK, Khang YH, Kim HC, Park JH, et al. : Cohort profile: the National Health Insurance Service-National Health Screening Cohort (NHIS-HEALS) in Korea. BMJ Open 7 : e016640, 2017

33. Simanek AM, Dowd JB, Pawelec G, Melzer D, Dutta A, Aiello AE : Seropositivity to cytomegalovirus, inflammation, all-cause and cardiovascular disease-related mortality in the United States. PLoS One 6 : e16103, 
Parkinson Disease and AMI | Sheen SH, et al.

2011

34. Sun Y, Chang YH, Chen HF, Su YH, Su HF, Li CY : Risk of Parkinson disease onset in patients with diabetes: a 9-year population-based cohort study with age and sex stratifications. Diabetes Care 35 : 1047-1049, 2012

35. Velseboer DC, de Haan RJ, Wieling W, Goldstein DS, de Bie RM : Prevalence of orthostatic hypotension in Parkinson's disease: a systematic review and meta-analysis. Parkinsonism Relat Disord 17 : 724-729, 2011

36. Verwoert GC, Mattace-Raso FU, Hofman A, Heeringa J, Stricker BH, Breteler MM, et al. : Orthostatic hypotension and risk of cardiovascular disease in elderly people: the Rotterdam study. J Am Geriatr Soc 56 : 1816-1820, 2008 